\title{
Algunas reflexiones en torno al rol de la cultura dentro de la investigación con motivo del décimo aniversario de The Weirdest People in the World?
}

\author{
Rafael Román Quirós
}

\author{
Universidad de Iberoamérica
}

\begin{abstract}
Resumen
El objetivo del presente artículo ha sido contribuir a la divulgación de los hallazgos a una década de la publicación de The Weirdest People in the World? (Heinrich, Heine y Norenzayan, 2010) para evidenciar la urgente necesidad y los potenciales aportes de los enfoques culturalmente sensibles en la actualidad dentro de las disciplinas que tienen como objeto de estudio la salud-enfermedad del ser humano. Dicha publicación generó revuelo no sólo en la psicología sino en diferentes disciplinas generando serias dudas respecto al verdadero objeto de estudio, estado actual y principales desafíos de la investigación.
\end{abstract}

Palabras clave: Cultura, psicología transcultural, WEIRD.

\section{(c) $(1)(\Theta \Theta$}




\section{Introducción}

Gordon Allport sostenía que la Teoría de los Humores es la doctrina más duradera en la historia respecto a la naturaleza humana, pues la misma no sólo ha estado presente desde la Edad Antigua, sino que además su influencia es palpable aún en nuestros libros de texto de Psicología actuales (Allport, 1937; Hothersal, 1997, Benjafield, 2015). Su desarrollo es el resultado de los descubrimientos y reflexiones en particular de Empédocles, Hipócrates y Galeno, si bien la misma es atribuída en esencia a Hipócrates (460-370 a.e.c.), el padre de la medicina occidental (Lukong, 2017). De esta manera, la teoría fue durante siglos el modelo dominante para entender el binomio salud-enfermedad (Hothersal, 1997).

La teoría hipocrática se encontraba en este sentido basada en la concepción de Empédocles en cuanto a la existencia de al menos cuatro sustancias o elementos dentro del arjé griego (la hermenéutica y filosofía de los principios); el agua, aire, fuego y tierra (Cassigoli, 2010; Woolford, 1999), elementos que obtenemos de la combinación de lo que se creía que eran las cuatro cualidades esenciales del cuerpo humano; el calor, frío, humedad y sequedad. De esta manera el cuerpo humano contendría cuatro elementos en consonancia con los anteriores elementos; del fuego la bilis amarilla, del agua la flema, del aire la sangre y de la tierra la bilis negra, todo lo cual en una combinación de balances resultaría determinante dentro del estado de salud-enfermedad, un estado que funcionaría de manera distinta para cada individuo en cuanto a la naturaleza de su propio cuerpo. De esta manera las intervenciones antiguas consistían en encontrar cuál de los humores se encontraba en desequilibrio, de manera en que se pudiera aumentar, disminuir o balancear las diferentes cualidades y cantidades de los mismos (Balzer y Eleftheriadis, 1991).

El rol de Galeno (129-216 e.c.) dentro de la teoría estuvo en expandir la misma a lo que se consideraría una tipología temperamental. De esta manera, la bilis amarilla correspondería a un carácter colérico e irritable, el agua correspondería a un carácter flemático, el cual en su exceso daría con personas apáticas, flojas y torpes, la sangre encontraría relación con un carácter sanguíneo característico de personas alegres y optimistas y por último la bilis negra daría como resultado un temperamento melancólico; solitario y no sociable (Doody e Immerwahr, 1983; Hothersal, 1997). Galeno asocia en este sentido una serie de elementos, estaciones y fluídos corporales; en el tanto el aire (elemento) compartiría con la primavera (estación) y la sangre (fluído) la característica de ser todos húmedos y calientes, de la misma forma en que por ejemplo la tierra y el otoño estarían en estrecha relación con el carácter melancólico, aspectos todos que desde su perspectiva compartían la característica de ser secos y fríos (Syros, 2013). Especialmente interesante en cuanto al

\section{pesco


carácter melancólico resulta la asociación que encuentra Galeno entre este y el cáncer de seno (tanto Galeno como Hipócrates creían que dicha afección se originaba debido a la acumulación de la bilis negra en el hígado) (Lukong, 2017) en el tanto se establece una relación entre la salud física y las predisposiciones emocionales; entre lo biológico y lo psicológico.

Desde 1977 se ha establecido el famoso Modelo Biopsicosocial desarrollado por Engel desde la Teoría General de Sistemas, un enfoque multidisciplinario que parte de que las enfermedades se atribuyen a la interacción entre la dimensión biológica, psicológica y adicionalmente; a la social (Kusnanto et al, 2018). De esta manera, dicho enfoque permitiría un abordaje de la enfermedad desde la interacción de sistemas celulares, de tejidos, órganos, de los aspectos interpersonales y también ambientales, partiendo del supuesto de que los factores psicosociales afectarían el desarrollo de las enfermedades, variando de unas a otras (Fava y Sonino, 2008).

En el 2007 una observación similar a la encontrada por Galeno respecto al cáncer de seno en mujeres de carácter melancólico es encontrada por Taylor et al. en un estudio en mujeres afrodescendientes en los Estados Unidos en cuanto a una débil correlación positiva entre dicho cáncer y la vivencia frecuente de experiencias de discriminación, especialmente entre mujeres jóvenes. De igual manera, en el 2014 Coogan et al., en un estudio con una muestra de 38,142, encuentran igualmente una correlación positiva entre el asma y las experiencias de racismo en mujeres negras en los Estados Unidos (aspecto último que desgraciadamente cuenta con una alta prevalencia en dicho país). De esta manera, el estrés crónico ante la discriminación percibida podría afectar el sistema inmunológico.

De igual forma, la prevalencia de Esclerosis Múltiple, una enfermedad inflamatoria crónica del Sistema Nervioso Central ha aumentado con el paso de tan sólo una cuantas décadas en la población de sexo femenino, no así masculino, con lo cual la prevalencia actual se establece entre el 2.3 ó el 3.5 de mujeres respecto a cada persona de sexo masculino (Ahlgren et al., 2011; Compston y Cole, 2002), una situación que ocurre de igual forma para distintas enfermedades autoinmunes (Compston y Cole, 2002) y todo lo cual mencionan algunos autores, podría deberse a aspectos aún sin identificar respecto a la nutrición o al entorno (Harbo et al, 2013); lo cual sugiere una vez más, una influencia del entorno en el sistema inmunológico y en el curso de distintas enfermedades. Es decir, la discriminación, un aspecto social, contextual y cultural influiría en el estrés psicológico (Clark et al., 1999) lo cual contribuiría en alguna medida a la aparición de una serie de enfermedades (Taylor et al., 2007).

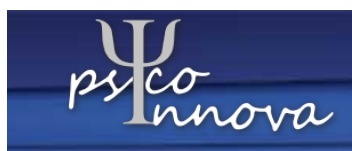


Lo anterior conlleva a que distintos profesionales de distintas disciplinas relacionadas a la salud se pregunten por ese entramado de valores y patrones conductuales que llamamos "cultura", un aspecto rara vez explorado a profundidad bajo el marco o encuadre de las Ciencias de la Salud; quizás porque no se argumenta su importancia desde una perspectiva pragmática o quizás por un entendimiento tácito de que la cultura es algo más bien propio de las Ciencias Sociales como la Psicología, la Sociología o en mayor medida, la Antropología; si bien tanto las Ciencias de la Salud como las Ciencias Sociales tienen el mismo objeto de estudio: el ser humano, el cual es un producto en toda su entereza de la integración de una serie de sistemas y subsistemas.

Si bien es cierto, es la complejidad que adquieren los diferentes campos y disciplinas científicas lo que ha llevado al paradigma de la especialización, al mismo tiempo puede el especialista ignorar vastas regiones de su propia disciplina. Hoy en día contamos con una serie de enfoques que intentan retornar a un análisis más integrado de lo que en un final resulta ser de todas formas, un ser humano, como por ejemplo la propuesta de Nielsen y Haun (2016) para la Psicología del Desarrollo, la cual consideran incompleta sin la pertinente perspectiva tanto de la Psicología Transcultural como de la Psicología Comparada. Ya lo decía Ernesto Sábato quien fuera no sólo el conocido escritor, sino también en alguna etapa de su vida, físico de profesión; la mayor revolución en el campo de la física fue llevada a cabo por Albert Einstein, quien al integrar los problemas más generales de la materia con el espacio y el tiempo, evidencia una vocación generalista (1987).

Con mayor razón, añadía Sábato, nos debemos preocupar por la integración cuando se trata de las complejas dimensiones biológicas y psicofísicas que supone cualquier disciplina o campo de estudio cuyo objeto sea finalmente, el ser humano. Sin embargo más allá de una apología al Uomo Universale del Renacimiento, existe una urgente y desconocida necesidad al menos en la disciplina psicológica, de reconocer la importancia de la dimensión cultural.

Por Cultura entendemos, una serie de patrones explícitos e implícitos de conducta adquiridos y transmitidos a través de símbolos, los cuales constituyen el logro distintivo de los grupos humanos, y cuyo centro esencial consiste en ideas históricamente derivadas y seleccionadas (ideas tradicionales) junto a distintos valores aparejados. Dichos sistemas culturales pueden ser considerados ya sea como productos de la acción o como elementos condicionantes para conductas subsecuentes (Kroeber y Kluckhohn, 1952). En este sentido, la cultura preserva y transmite diferentes tipos de herencias sociales como creencias, convenciones o normas (Cole y Parker, 2011) que incluyen formas rutinarias de pensar, de

\section{psco


sentir y de interactuar con otras personas, así como ideas acerca del mundo que suelen compartirse entre individuos interconectados que a menudo suelen estar demarcadas por aspectos como la raza, etnia o la nacionalidad (Hong, 2009).

Esto quiere decir que el término cultura puede referirse tanto a la cultura costarricense vallecentralina, como a la cultura vegetariana, a la cultura millenial, etc (Heine, 2016). En este sentido, hay una cultura en particular que nos ayuda a entender tanto la utilidad de hacer investigación culturalmente sensible, como de la urgente necesidad y fragilidad que tiene la disciplina en la actualidad; la cultura WEIRD.

Decía Schweder, para muchos el padre de la Psicología Cultural, que la mayor parte de lo que se ha denominado la Psicología General, inherentemente asume que la mente funciona mediante leyes naturales generalizables para todas las personas, independientemente de las experiencias y del contexto (Schweder, 1990), cuando la realidad es que los individuos de distintas culturas difieren en aspectos tan básicos como la forma en que perciben el mundo, aquello que les resulta correcto o incorrecto, o en cuanto a un sinfín de motivaciones y conductas (Heine, 2016). El acrónimo WEIRD se refiere a personas o muestras occidentales (Western), con cierto nivel educativo (Educated), de países industrializados (Industrialized), desarrollados (Rich) y democráticos (Democratic) (Henrich, Heine y Norenzayan, 2010). Específicamente bajo la designación "cultura occidental" (Western culture) nos indica Heine (2016) que los distintos autores usualmente se refieren a países ubicados en el noroeste europeo y a sociedades de descendencia británica, como es el caso de Australia, Estados Unidos y Canadá.

El acrónimo acuñado por Heinrich et al (2010) se hace inicialmente en referencia a un estudio de Arnett (2008) que determina que el 95\% de las muestras para publicaciones en revistas psicológicas de primer nivel sobre seis subdisciplinas entre el 2003 y el 2007 eran precisamente muestras WEIRD, es decir, en gran medida; estudiantes universitarios. Ya incluso en 1986 encontramos una publicación que advertía que la investigación basada en estudiantes universitarios realizando tareas muy similares a las propias de los ambientes académicos daría al traste con el desarrollo de teorías incompatibles con el mundo no académico (Sears, 1986). La investigación de Arnett (2008) encuentra adicionalmente que el $68 \%$ de las publicaciones además, obtenían sus hallazgos de muestras estadounidenses siendo que el mundo desarrollado occidental (que comparte las características WEIRD) representa tan sólo al $12 \%$ de la población mundial. Es decir, ¿reproducimos, aprendemos y producimos (en el menor de los casos) teoría y hallazgos sobre la psicología y la conducta humana; o más bien dominamos teorías y hallazgos aplicables y generalizables tan sólo para estudiantes universitarios norteamericanos y del primer mundo?

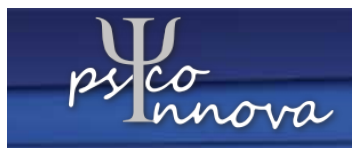


El estudio de Heinrich et al (2010) se propuso comparar resultados experimentales de personas de sociedades industrializadas modernas respecto a personas de sociedades no occidentales, más pequeñas y menos desarrolladas; incluso comparando a universitarios estadounidenses con estadounidenses sin una formación universitaria, encontrando una variabilidad significativa en procesos psicológicos básicos, como lo son estilos de razonamiento, la categorización, el razonamiento inductivo, en razonamiento espacial, la percepción visual, el razonamiento moral, el sentido de justicia, conductas de cooperación y el autoconcepto, sustentando con ello el principal hallazgo del estudio: las sociedades WEIRD se encuentran entre las poblaciones menos representativas que se pueden encontrar para hacer hallazgos generalizables sobre los seres humanos. Es decir, no sólo hemos sobre estudiado una tajada poblacional muy pequeña de los seres humanos, sino que además muchas de nuestras leyes generales provienen de una sección humana muy poco representativa.

Esto no quiere decir de ninguna manera que la Psicología carezca de hallazgos con un robusto sustento empírico. Tomemos por ejemplo el caso de la personalidad. Dicho constructo, para serlo, requiere de 2 condiciones; en primer lugar que la estructura interna de los individuos goce de cierta estabilidad con el paso del tiempo y en segundo, requiere que las mismas tipologías sean encontradas en distintas culturas (Mishel y Shoda, 1998); caso contrario, no estaríamos estudiando la personalidad, sino el influjo de la cultura en los individuos. Es decir, necesitaríamos en este caso de constructos y factores que gocen de cierta estabilidad transcultural, para lo cual hay evidencia robusta.

En este sentido, en las últimas tres décadas, el marco dominante dentro de la Psicología para trabajar con los rasgos de personalidad ha sido el Modelo de los cinco grandes de Goldberg (1990) (Gerber et al, 2011), mejor conocido como el Big Five: 1) extraversiónintroversión 2) neuroticismo-estabilidad emocional 3) apertura a la experiencia 4) afabilidadoposicionismo y 5) el factor denominado conscientiousness, en ocasiones traducido al español como escrupulosidad (Rodríguez-Sánchez, 2008; Kausel et al, 2012). Los mismos cinco factores a excepción de unas pocas excepciones han emergido en investigaciones en distintas culturas, fundamentando el postulado de que dichas tipologías en cuestión, son universales (McRae et al, 2005; Schmitt et al, 2007; Rolland, 2002). Sin embargo y volviendo al argumento transcultural, dichas investigaciones provienen en su basta mayoría de muestras que podríamos llamar occidentalizadas (McRae et al, 2005); lo que ha generado críticas en torno a la verdadera universalidad del modelo (Bailey et al, 2013; Gurven et al, 2013; Laajaj

\section{psico


et al, 2019); ¿estudiamos a los humanos en general, o estudiamos ciertos humanos con ciertas características?

Por ejemplo Gurven et al (2013), al estudiar el ajuste del modelo de cinco factores entre los Tsimanes, un pueblo originario en Bolivia, encuentran que el mejor ajuste es de hecho de dos factores que no encuentran relación con ninguno del modelo de Goldberg (1990); sino que más bien se obtiene respectivamente un factor que contiene elementos que denotan laboriosidad y otro que apunta hacia una actitud prosocial. De paso, resulta interesante que los autores se adelanten en advertir y enfatizar que su propuesta metodológica es rigurosa en pruebas y procedimientos de análisis; ya que sostienen que en las ocasiones en que no hay un ajuste al modelo de los cinco factores en muestras no occidentales (Piedmont et al, 2002; Schmitt el al, 2007; Triandis, 1997), se arguye con frecuencia que esto podría deberse a problemas metodológicos que evitan la replicación de los resultados.

Si bien hemos ido incorporando desde la Edad Antigua las diferentes dimensiones de lo humano dentro del binomio salud-enfermedad, paradójicamente el paradigma de la especialización podría haber contribuido a una generalización gravemente sesgada en nuestra disciplina. Es curioso que Francis Bacon ya desde el Renacimiento nos advirtiera sobre sus famosos Ídolos; cinco malos hábitos inherentes a la naturaleza humana que nos hacen caer en el error (Russell, 2009), y entre los cuales se encontraba precisamente los Ídolos de la Tribu: la tendencia a generalizar a partir de nuestra propia vida comunitaria. Es cierto que la ciencia tiene una finalidad nomotética que aspira a desarrollar leyes y conocimientos que nos permitan predecir con cierto grado de certeza. Pero también nos advertía Bacon sobre lo crucialmente importantes que resultan para el conocimiento aquellos casos que constituyen excepciones a la norma (Buckingham et al, 2017); aspectos que desde lo ideográfico nos ofrecen un conocimiento y una explicación más completa respecto a los fenómenos. Una lección más para las disciplinas científicas en cuanto a que a pesar de sus avances, no deberían nunca relegar a la filosofía.

Evidentemente existe en nuestro panorama actual de pandemia una utilidad importante en la comprensión de excepciones empíricas en investigaciones respecto a todo aquello que nos permita afrontar la difícil situación. Sin embargo hay otro aspecto importante dentro de los enfoques culturalmente sensibles, la utilidad que pueda tener para nosotros la variabilidad cultural, pues, como sostienen Cole y Parker (2011), la cultura es un medio para preparar a los humanos para su interacción con el mundo. Lidiamos con una situación difícil que hay que afrontar, a la cual hay que adaptarse, y diferentes culturas desarrollarán diferentes formas de llevarlo a cabo.

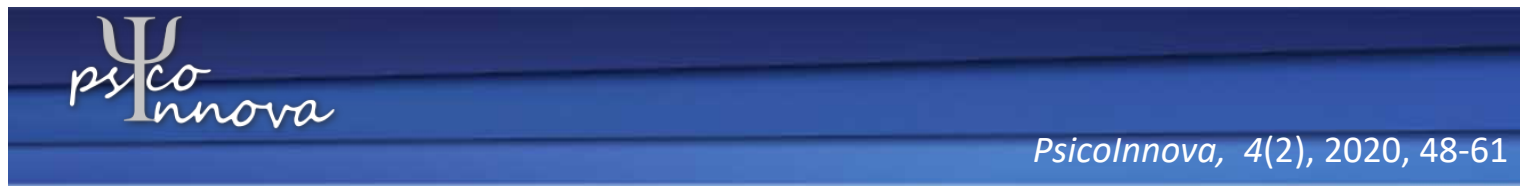


Existen enfermedades que encuentra una mayor o menor prevalencia entre una región u otra debido a aspectos culturales (Murray y Schaller, 2010). Cultivar especias, por ejemplo, ha sido una forma de afrontamiento desarrollada por culturas en las que por su clima y prácticas culturales, la infestación bacterial de los alimentos ha constituido históricamente un problema. Cultivar especias requiere de recursos para dichos aditivos, los cuales no resultan especialmente nutricionales, sino que es su poderoso efecto antibiótico lo que las ha hecho populares en estas regiones (Sherman y Billing, 1999). De esta manera la forma de adaptarse y afrontar una enfermedad puede encontrarse incluso en un aspecto aparentemente intrascendente; la cocina.

Otras formas culturales de afrontar enfermedades pueden ser encontradas en las preferencias de emparejamiento; en el tanto regiones con mayores niveles de patógenos habrían priorizado el atractivo físico (Gangestad y Buss,1993). Las religiones a su vez involucran una serie de prácticas que de igual forma han sido consideradas por algunos autores como estrategias para lidiar con enfermedades infecciosas (Fincher et al, 2008). Incluso las características culturales de conducta interpersonal podrían ser también formas de afrontar enfermedades infecciosas, en el tanto la apertura a la experiencia y la extroversión han mostrado ser menores en regiones con una mayor prevalencia de enfermedades infecciosas (Schaller y Murray, 2008).

Diez años han transcurrido desde la famosa publicación de Heinrich, Heine y Norenzayan (2010) que conmocionó a la disciplina psicológica y que popularizó el acrónimo WEIRD; ahora de uso común en varias disciplinas (Clancy y Davis, 2019). A pesar de que la variabilidad cultural y los enfoques culturales y transculturales de investigación podrían ofrecer en un contexto como el actual alternativas para afrontar una pandemia por ejemplo (sean estas del tipo que sean); lastimosamente las complejas relaciones que operan con las distintas variables ecológicas rara vez son objeto de investigación (Murray y Schaller, 2010). Difícilmente tendremos investigación cultural o transcultural si estos enfoques de la psicología no son siquiera conocidos dentro de la disciplina misma. Por esta razón, el presente artículo se ha propuesto al menos el haber contribuido como un primer paso no sólo al homenaje de una década transcurrida desde dicha publicación, sino también a la divulgación de dichos hallazgos que resultan cruciales para todo aquel profesional que quiera ahondar en el verdadero objeto, estado actual y los principales desafíos de su disciplina. 
"La casa se desocupó y no quedó ni un solo habitante: nadie salvo el médico y la enferma. Dulcemente le dijo: ¿De qué ciudad provienes? Pues es distinto el tratamiento para las personas de cada lugar. Y en esa ciudad, ¿qué relaciones tienes? ¿Con quién estás emparentada, o hacia quién sientes afinidad?” (Rumi, p. 25, Mathnawi).

\section{Referencias}

Ahlgren, C., Odén, A., y Lycke, J. (2011). High nationwide prevalence of multiple sclerosis in Sweden. Multiple sclerosis (Houndmills, Basingstoke, England), 17(8), 901-908. https://doi.org/10.1177/1352458511403794

Allport, G. W. (1937). Personality, a psychological interpretation. New York: Henry Holt and Co.

Arnett J. J. (2008). The neglected 95\%: why American psychology needs to become less American. The American psychologist, 63(7), 602-614. https://doi.org/10.1037/0003066X.63.7.602

Balzer, W. y Eleftheriadis, A. (1991). A reconstruction of the Hippocratic Humoral Theory of Health. Journal for General Philosophy of Science, 22(2), 207-227.

Bailey, D. H., Walker, R. S., Blomquist, G. E., Hill, K. R., Hurtado, A. M., y Geary, D. C. (2013). Heritability and fitness correlates of personality in the ache, a natural-fertility population in Paraguay. PLoS One, 8(3). https://doi.org/10.1371/ journal.pone.0059325.

Benjafield, J. G. (2015). A History of Psychology. (4a Ed.). Canadá: Oxford University Press.

Buckingham, W., Marenbon, J., Burnham, D., Weeks, M., Hill, C., King, P. J. (2017). The Philosophy Book. Big Ideas Simply Explained. (2da ed.). Reino Unido: Dorling Kindersley Limited.

Cassigoli, R. (2010). Memoria, historia y praxis. Historia, antropología y fuentes orales. 44, 97-112. 
Clancy, K., y Davis, J. L. (2019). Soylent is people and WEIRD is white: Biological anthropology whiteness and the limits of the WEIRD. Annual Review of Anthropology. 48, 179-186. https://doi.org/10.1146/annurev-anthro-102218-011133

Clark R, Anderson N.B., Clark, V.R. y Williams, D.R. (1999). Racism as a stressor for African-Americans. A biopsychosocial model. The American Psychologist, 54(10), 805-816. https://doi.org/10.1037//0003-066x.54.10.805

Cole, M., y Parker, M. (2011). Culture and cognition. In K. D. Keith (Ed.), Cross-cultural psychology: Contemporary themes and perspectives (pp. 133-159). Chichester, UK: Wiley- Blackwell.

Compston, A., y Coles, A. (2002). Multiple sclerosis. Lancet (London, England), 359(9313), 1221-1231. https://doi.org/10.1016/S0140-6736(02)08220-X

Coogan, P. F., Yu, J., O'Connor, G. T., Brown, T. A., Cozier, Y. C., Palmer, J. R., y Rosenberg, L. (2014). Experiences of Racism and the Incidence of Adult-Onset Asthma in the Black Women's Health Study. Chest, 145,(3). 480-485. 10.1378/chest.13-0665

Doody, J. A. e Immerwahr, J. (1983). The persistence of the four temperaments. Soundings: An Interdisciplinary Journal, 66(3). 348-359.

Fava, G. A. y Sonino, N. (2008). The Biopsychosocial Model Thirty Years Later. Psychotherapy and Psychosomatics, 77. 10.1159/000110052

Fincher, C. L., Thornhill, R., Murray, D. R., y Schaller, M. (2008). Pathogen prevalence predicts human cross-cultural variability in individualism/collectivism. Proceedings. Biological sciences, 275(1640), 1279-1285. https://doi.org/10.1098/rspb.2008.0094

Gangestad, S. W., y Buss, D. M. (1993). Pathogen prevalence and human mate preferences. Ethology and Sociobiology, 14, 89-96.

Gerber, A. S., Huber, G. A., Doherty, D., y Dowling, C. M. (2011). The Big Five Personality Traits in the political arena. Annual Review of Political Science, 14, 265-287.

Goldberg, L. R. (1990). An alternative "description of personality": the Big-Five factor structure. Journal of Personality and Social Psychology. 59, 1216-1229. DOI: $\underline{10.1037 / / 0022-3514.59 .6 .1216}$

\section{pstco


Gurven, M., von Rueden, C., Massenkoff, M., Kaplan, H., \& Lero Vie, M. (2013). How universal is the Big Five? Testing the five-factor model of personality variation among forager-farmers in the Bolivian Amazon. Journal of Personality and Social Psychology, 104(2), 354-370. https://doi.org/10.1037/a0030841.

Harbo, H. F., Gold, R., Tintoré, M. (2013). Sex and gender issues in multiple sclerosis. Therapeutic advances in neurological disorders, 6(4). 237-248. doi: $10.1177 / 1756285613488434$

Heine, S. J. (2016). Cultural Psychology. (3 ed). New York:W. W. Norton and Company

Henrich, J., Heine, S. J., y Norenzayan, A. (2010). The weirdest people in the world?. The Behavioral and brain sciences, 33(2-3), 61-135. https://doi.org/10.1017/S0140525X0999152X

Hong, Y. (2009). A dynamic constructivist approach to culture: Moving from describing culture to explaining culture. In R. S. Wyer, C.-Y. Chiu, \& Y.-Y. Hong (Eds.), Understanding culture: Theory, research and application (pp. 3-23). New York, NY: Psychology Press.

Harbo, H. F., Gold, R., y Tintoré, M. (2013). Sex and gender issues in Multiple Sclerosis. Theurapeutic Advances in Neurological Disorders. 6(4), 237-248. 10.1177/ 1756285613488434

Hothersall, D. (1997). Historia de la Psicología. (3ed). México: Editorial McGraw Hill.

Kausel, E., Leiva, P. I., Sanfuentes, M., y Barros, E. (2012). Más allá de los cinco grandes: disposiciones y personalidad en la predicción de decisiones deshonestas en el contexto organizacional. Innovar. [Revista de Ciencias Administrativas y Sociales]. 22(44),109122. https://www.redalyc.org/articulo.oa?id=818/81824866009

Kusnanto, H., Agustian, D., y Hilmanto, D. (2018). Biopsychosocial model of illnesses in primary care: A hermeneutic literature review. Journal of family medicine and primary care, 7(3), 497-500. https://doi.org/10.4103/jfmpc.jfmpc_145_17

Kroeber, A. L., y Kluckhohn, C. (1952). Culture: A critical review of concepts and definitions. Cambridge, MA: Peabody Museum. 
Laajaj, R., Macours, K., Pinzon Hernandez, D. A., Arias, O., Gosling, S. D., Potter, J., ... Vakis, R. (2019). Challenges to capture the big five personality traits in non-WEIRD populations. Science Advances, 5(7). https://doi.org/10.1126/sciadv. aaw5226.

Lukong, K.E. (2017). Understanding breast cancer - The long and winding road. BBA Clinical, 7, 64-77 doi:10.1016/j.bbacli.2017.01.001

McCrae, R. R., Terracciano, A., y Personality Profiles of Cultures Project. (2005). Universal features of personality traits from the observer's perspective: data from 50 cultures. Journal of personality and social psychology, 88(3), 547-561. https://doi.org/10.1037/0022-3514.88.3.547

Mishel, W., y Shoda, Y. (1998). Reconciling processing dynamics and personality dispositions. Annual Review of Psychology, 49, 229-258.

Murray, D. R. y Schaller, M. (2010). Historical Prevalence of Infectious Diseases Within 230 Geopolitical Regions: A Tool for Investigating Origins of Culture. Journal of Cross-Cultural Psychology. 41(1). 99-108.

Nielsen, M., y Haun, D. (2016). Why developmental psychology is incomplete without comparative and cross-cultural perspectives. Philosophical transactions of the Royal Society of London. Series B, Biological sciences, 371(1686). https://doi.org/10.1098/rstb.2015.0071

Piedmont, R. L., Bain, E., McCrae, R. R., y Costa, P. T., Jr. (2002). The applicability of the five-factor model in a sub-Saharan culture: The NEO-PI-R in Shona. In R. R. McCrae $\&$ J. Allik (Eds.), The five-factor model of personality across cultures (155-173). New York, NY: Kluwer Academic.

Rodríguez-Sánchez, S. (2008). Estudio sobre las percepciones de estabilidad o cambio en la personalidad durante la etapa adulta. International Journal of Developmental and Educational Psychology, 1(1),269-277. https://www.redalyc.org/articulo.oa?id=349832316028 
Rolland, J. P. (2002). Cross-cultural generalizability of the five-factor model of personality. En R. R. McCrae y J. Allik (Eds.), The five-factor model of personality across cultures (7-28). New York: Kluwer Academic/Plenum Publishers

Russell, B. (2009). Historia de la Filosofía [History of the Western Philosophy]. RBA Coleccionables. (Original work published 1945)

Rumi [Maulana Jalal al Din Rumi]. (1273). Mathnawi. [Versión de R. A. Nichols]: epublibre

Sábato, E. (1987). La Robotización del Hombre y otras páginas. (1ª ed.). Argentina: Centro Editor de América Latina (CEDAL).

Sears, D. O. (1986). College sophomores in the laboratory: Influences of a narrow data base on social psychology's view of human nature. Journal of Personality and Social Psychology, 51(3), 515-530. https://doi.org/10.1037/0022-3514.51.3.515

Schaller, M., y Murray, D. R. (2008). Pathogens, personality, and culture: Disease prevalence predicts worldwide variability in sociosexuality, extraversion, and openness to experience. Journal of Personality and Social Psychology, 95(1), 212-221. DOI: 10.1037/0022-3514.95.1.212

Schmitt, D. P., Allik, J., Mccrae, R. R., y Benet-Martínez, V. (2007). The Geographic Distribution of Big Five Personality Traits: Patterns and Profiles of Human SelfDescription Across 56 Nations. Journal of Cross-Cultural Psychology, 38(2), 173-212. https://doi.org/10.1177/0022022106297299

Schweder, R. A. (1990). Cultural psychology: what is it? En J. W. Stigler, R. A. Shweder, and G. Herdt (Eds.), Cultural Psychology: Essays on comparative human development (p. 1-43). Cambridge, England: Cambridge University Press.

Sherman, P. W. y Billing, J. (1999). Darwinian Gastronomy: Why we use spices. BioScience, 49(6), 453-463. https://doi.org/10.2307/1313553

Syros, V. (2013). Galenic Medicine and Social Stability in Early Modern Florence and the Islamic Empires. Journal of Early Modern History, 17, 161-213. DOI: $10.1163 / 15701658-12342361$ 
Taylor, T., Williams, C., Makambi, K., Mouton, C., Harrel, J., Cozier, Y., Palmer, J., Rosenberg, L., Adams-Campbell, L. (2007). Racial discrimination and breast cancer incidence in US black women. American Journal of Epidemiology, 166(1). 10.1093/aje/kwm056

Triandis, H. (1997). Cross-cultural perspectives on personality. In R. Hogan, J. Johnson, \& S. Briggs (Eds.), Handbook of personality psy-chology (pp. 439-464). San Diego, CA: Academic Press.

Woolford, J. (1999). Arnold on Empedocles. The Review of English Studies, New Series, 50 (197), 32-52. 